\title{
Exposure as Collected Domain
}

National Cancer Institute

\section{Source}

National Cancer Institute. Exposure as Collected Domain. NCI Thesaurus. Code 6117466.

This interventions domain model reflects protocol-specified study treatment administrations, as collected. 